\title{
Aerosol Number Concentrations and Visibility during Dense Fog over a Subtropical Urban Site
}

\author{
Manju Mohan ${ }^{1}$ and Swagata Payra ${ }^{1,2}$ \\ ${ }^{1}$ Centre for Atmospheric Sciences, Indian Institute of Technology Delhi, Hauz Khas, New Delhi 110016, India \\ ${ }^{2}$ Centre of Excellence in Climatology, BIT Mesra, Extension Centre Jaipur, 27 MIA Jaipur, Rajasthan 302 017, India \\ Correspondence should be addressed to Manju Mohan; mmohan66@gmail.com
}

Received 25 April 2014; Revised 1 July 2014; Accepted 1 July 2014; Published 11 August 2014

Academic Editor: Prashant Kumar

Copyright (c) 2014 M. Mohan and S. Payra. This is an open access article distributed under the Creative Commons Attribution License, which permits unrestricted use, distribution, and reproduction in any medium, provided the original work is properly cited.

\begin{abstract}
There is now enough evidence of greater frequencies and extent of fog formation in urban areas. These could easily be linked to rapid increase in aerosol number concentration (ANC) peculiar to polluted urban environments. It is therefore pertinent to study ANC and visibility alongside the meteorological parameters in order to investigate the relationships which may possibly exist between these parameters especially during foggy conditions. This study based on field measurements of ANC for aerosol spectrum varying from $0.3 \mu \mathrm{m}$ to $20 \mu \mathrm{m}$ attempts to investigates whether a threshold ANC could be associated with a given visibility range during low visibility conditions including dense fog episodes. Thus, the present work explores relationship between ANC size spectrum and visibility $(100 \mathrm{~m}-4500 \mathrm{~m})$ in a polluted urban environment in India with specific reference to episodes of dense fog during winter period. The study depicts a threshold minimum value of ANC during foggy conditions. A power relationship between ANC and visibility is obtained. Further, aerosol number distribution and size distribution function are also studied and empirical relation is compared with previous studies. Further work is suggested to strengthen the findings presented here.
\end{abstract}

\section{Introduction}

Fog formation occurs typically in aerosol-laden surface air under high relative humidity, ranging from undersaturated to slightly supersaturated conditions [1]. Aerosols act as nuclei for water vapor to condense onto and therefore fog is more likely to occur in an environment with high concentrations of hygroscopic aerosols [2].

Delhi is considered to be highly polluted in terms of particulate pollution that often exceeds the air quality standards [3]. Megacity Delhi is located in semiarid climate zone in North India. It is worth mentioning that only few studies are reported that include aerosol number concentration (ANC) and visibility during fog $[4,5]$. There are some recent studies related to fog over Delhi [6-10]. Amongst these studies, Mohan and Payra, 2009 [9], explore ANC and visibility related issues during fog. They studied visibility and ANC during winter season of 2004 and 2006 in a qualitative manner where air pollutant concentrations were shown to be correlated with the daily episodes of fog. Scattering of solar radiation by aerosols is the main process limiting visibility in the troposphere. Atmospheric aerosols in the accumulation mode efficiently scatter the solar radiation because their size is of the same order as that of the wavelength of radiation and hence accumulation mode aerosols can reduce visibility to a greater extent due to increased scattering and hence exacerbate the process of fog formation.

Aerosols in accumulation mode greatly affect the fog formation. Willeke and Whitby [11] have shown a relationship between aerosol number distributions with aerosol size spectrum based on observations. Significant variability has been observed in the droplet size distribution (DSD) in fog. In addition to the size, ionic composition of fog water can also indicate greater chances of fog formation if it is hydrophilic in nature. Based on the study by Ali et al. [6] of the fog water over Delhi during 2001-2003, it was pointed out that hydrophilic ions such as sulfate and nitrate chloride are more prevalent which are of anthropogenic origin from sources such as industries and transport. Therefore increasing aerosol concentrations are more likely to have a key role to 
play in enhancing condensation of water over these aerosols. Condensation of water vapour is exacerbated in polluted environment with increasing ANC due to increase in condensation nuclei often of very small size due to anthropogenic origin. This in turn would lead to the formation of large number of small size droplets (instead of small number of large size droplets in natural environment) resulting in relatively enhanced degradation in visibility due to Twomey effect [12]. However, Kohler theory suggests the growth of the large number of small size droplets up to a certain point beyond which the Kelvin effect predominates. Kohler curve between saturation ratio (ratio of vapor pressure of a solvent over a solution droplet to its pure component vapour pressure over a flat surface saturation at the same temperature) and droplet diameter $D$ represents a region where the growth of the droplet is dominated by solute effects till it attains a saturation ratio $S$, of unity at which point the droplet diameter is named potential diameter Dp. When saturation ratio becomes greater than 1, Kelvin effect predominates significantly over the solute effects and beyond a point when it exceeds a critical saturation ratio $S_{c}$ (at this point the saturation ratio is maximum) and the critical diameter, $D_{\mathrm{pc}}$, whatever the size of the drop, its equilibrium vapour pressure is less than that with which it is in contact and growth continues indefinitely. It is, in fact, through this process that cloud or fog droplets grow in diameter [13]. This would limit the growth of large number of small size droplets indefinitely. These constraints are likely to result in a threshold ANC (or a minimum ANC) for a particular size in the aerosol spectrum associated with a particular range of visibility during fog episodes. Fog occurs in Delhi during winter season when meteorological conditions are favourable such as low temperatures, low wind, and high relative humidity. A study by Mohan and Payra [9] based on the visibility data over 11962001 during winter season (November to February) shows that fog occurrences were $58 \%$.

Based on the above background, measurements of aerosol number concentration spectrum in different size range, relevant meteorological parameters, and visibility during winter season encompassing dense fog episodes were undertaken for a polluted urban environment such as megacity Delhi. The aim of this study is to explore the relationships that exist between ANC, aerosol size distribution (ASD), and visibility with special attention to low visibility episodes.

\section{Experimental Plan}

The GRIMM Aerosol Monitor (Model 1.108), which is an optical particle counter (OPC), is a 15-channel aerosol spectrometer that can measure ANC in 15 different size ranges which are $0.3,0.4,0.5,0.65,0.8,1,1.6,2,3,4,5,7.5,10,15$, and $20 \mu \mathrm{m}$ and the total number concentration of particles (sum total of ANC in all 15 different ASD). Diameters were measured as optical diameters as described by Peters et al. [14]. Counting of aerosols is accomplished by light scattering with the help of laser ray. Simultaneously, constant flow rate (1.2 litre/min) is maintained with air volume control system throughout the measurements. GRIMM Portable aerosol spectrophotometer has particle counting capability of 1000-2 $\times 10^{6}$ particles litre ${ }^{-1}$. The reproducibility of the instrument is $\pm 3 \%$ over the whole measuring range (GRIMM OPC Manual [15]). Performance of GRIMM for fine size particles has also been evaluated and acknowledged in past studies.

Half hourly averaged ANC measurements were conducted continuously during winter season for the period December 2, 2006, to January 16, 2007, that is characterized by adequate number of low visibility episodes of fog. The measurements were conducted on top of a building of the Indian Institute of Technology at Delhi (IIT-D). IIT Campus is mainly residential with an area of 320 acres which is surrounded by roads with moderate traffic density. The distance of nearest road from the measurement site is $200 \mathrm{~m}$. The inlets for aerosol measurements were mounted on the roof of the building and were about $10 \mathrm{~m}$ above the ground. All meteorological data for this study (2006-2007) are taken for the Safdarjung station of India Meteorological Department (IMD). Figure 1 shows a map of Delhi with some important locations along with the measurement site. The IMD measures visibility with the help of transmissometer with a 30 -minute temporal and $5 \mathrm{~km}$ spatial resolution. It works on the physical principal of inverse total extinction and operates by sending a narrow, collimated beam of energy (usually a laser) through the propagation medium at $550 \mathrm{~nm}$ [10].

\section{Results and Discussion}

Figure 2 shows half-hourly variations of visibility from December 2, 2006, to January 16, 2007. It also depicts that visibility drops suddenly characteristically when fog formation takes place. Figure 2 also encircles three time periods indicating episodes of dense fog. Figure 3 shows one of these dense fog episodes more clearly in detail where the visibility drops up to $100 \mathrm{~m}$.

Figure 3 illustrates the relationship between aerosol number concentration and visibility along with relative humidity $(\mathrm{RH})$ during December 31, to January 1 . Wind speed was light and favourable for the formation of fog as neither calm winds nor high wind speeds sustain foggy conditions. Figure 4 shows the wind rose over Delhi during the study period where prominently the wind direction is from West and North-West and South-West sectors. The prominent land-use land cover (LULC) in these directions is residential and cropland type with no heavy industries or any other significant emission sources. Characteristic of tropical climate, significant calm wind conditions are also seen (35.28\%) during the study period implying stagnation conditions. The dense fog episode starts on December 31, 2006, at 11 p.m. and finishes at 6.30 a.m. on the following day. Relative humidity is depicted on Figure 3 for each half-hour, which is above $88 \%$ in all cases apart from few points. For comparative assessment, ANC variations are shown during as well as several hours before and after the dense fog formation. It is clearly revealed in this figure that low visibility conditions are associated with higher values of ANC during the fog initiation and vice versa. Figure 3 also reveals that when visibility is equal to or less 


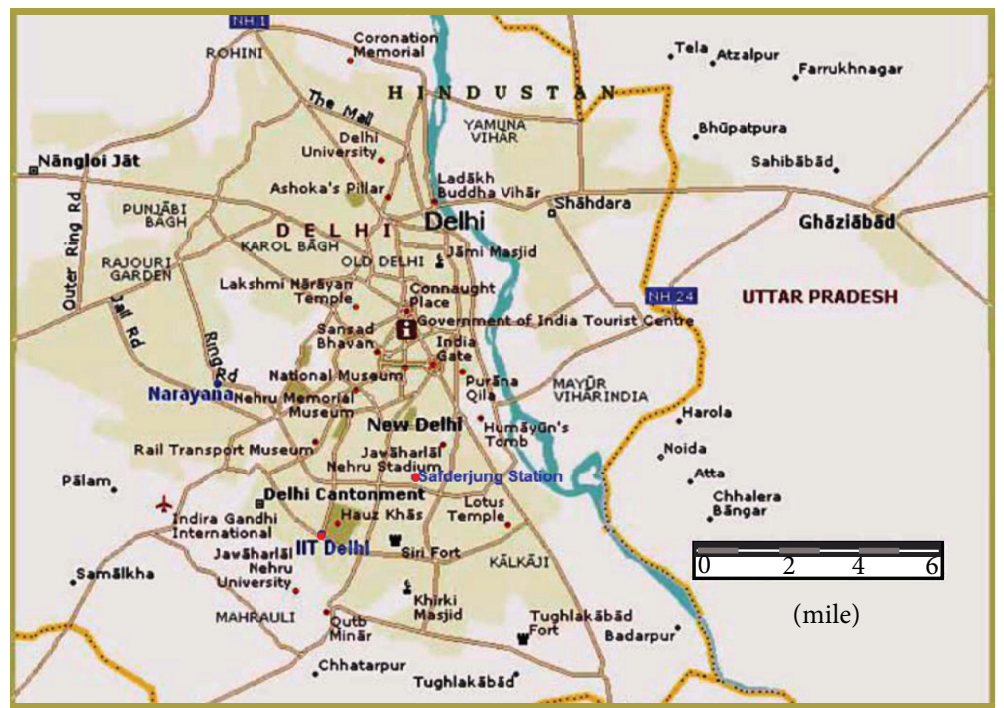

FIgURE 1: Map of Delhi showing measurement site and other important locations.

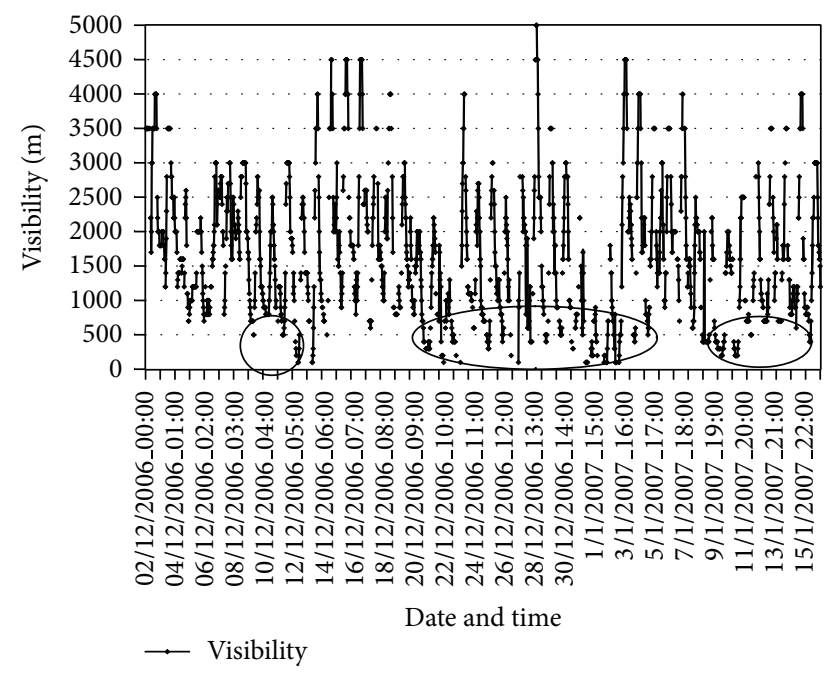

FIgURE 2: Time series of visibility during experiments from December 31, 2006, to January 15, 2007.

than $1000 \mathrm{~m}$ (fog episodes), the ANC is always of the order of $10^{6}$. However, the visibility was quite high for ANC of the order of $10^{5}$. Thus a relationship between ANC and visibility could be expected. Hence, ANC and visibility correlations are studied. As the measurements cover 15 bins, based on correlation studies of ANC with various combinations of size bins, we have selected two separate windows for further study, namely, ANC-I and ANC-II. ANC-I varies from $0.3 \mu \mathrm{m}$ to $0.8 \mu \mathrm{m}$ and ANC-II varies from greater than $0.8 \mu \mathrm{m}$ to $20 \mu \mathrm{m}$. The correlation coefficient between ANC-I and visibility is -0.76 whereas the correlation coefficient between ANC-II and visibility is -0.53 . Better correlation of visibility with ANC-I is expected as this is the closest measured window to the wavelength of visible light $(0.39 \mu \mathrm{m}-0.7 \mu \mathrm{m})$ that is mostly responsible for visibility reduction due to Mie

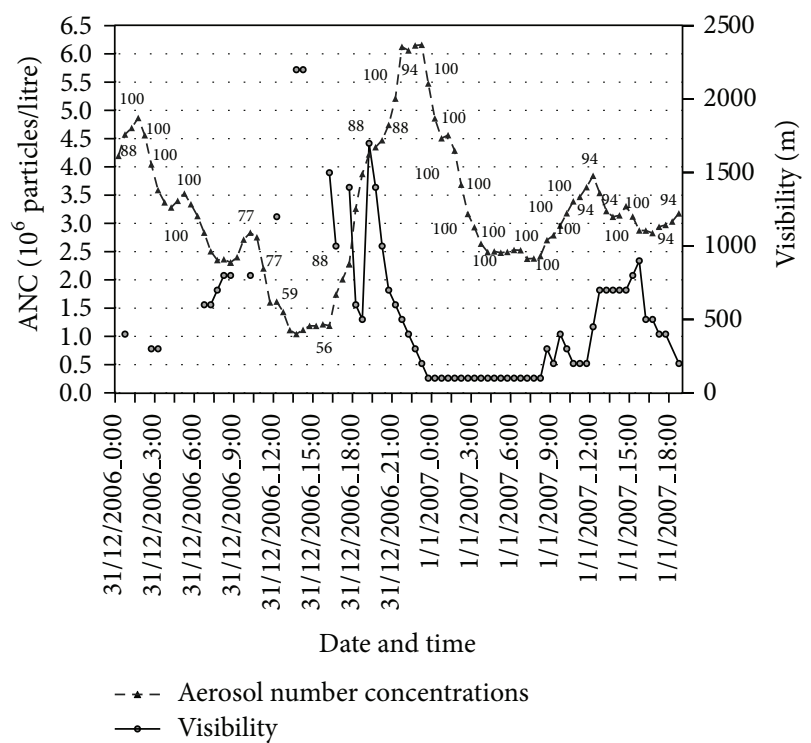

FIgURE 3: Time series of visibility, ANC, and RH during dense fog episode (December 31, 2006, to January 1, 2007). The numerical value of $\mathrm{RH}$ is denoted on the ANC curve.

scattering. ANC is significantly large in ANC-I window and it shows better correlation in comparison to ANC-II window. Moreover ANC-I shows higher ANC as well and that should exacerbate the visibility reduction further. Thus quantitative analysis of ANC-I size bin is investigated further.

Figure 5 depicts ANC and visibility variations in the ANC-I window. This figure also clearly shows that the visibility decreases as the aerosol number concentration increases. Based on the ANC and visibility data as also shown in Figure 5, threshold number concentration (i.e., a minimum number above which a particular visibility is observed) is about $2.0 \times 10^{6}$ particle/litre for visibility of about 


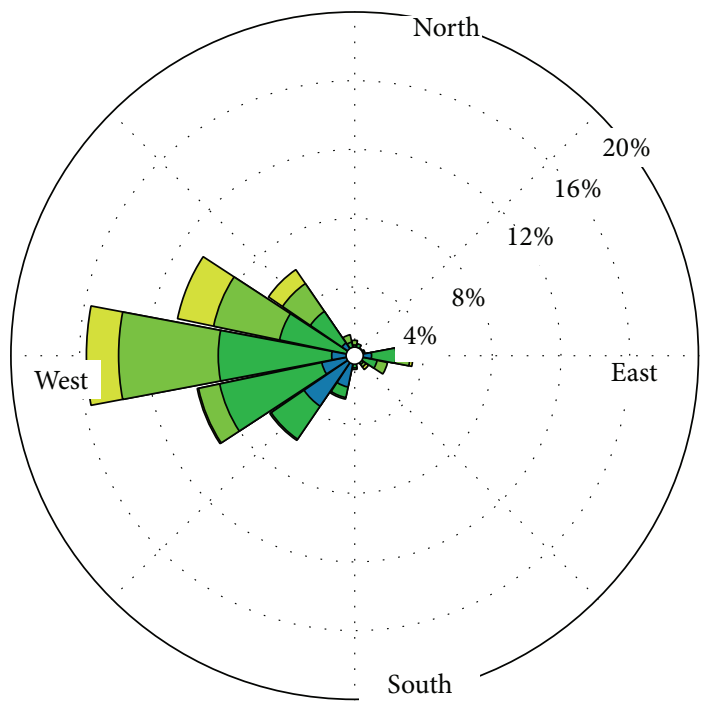

Wind speed $(\mathrm{m} / \mathrm{s})$

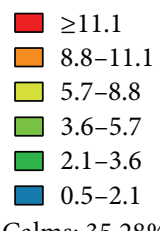

Figure 4: Wind rose over Delhi during December 2, 2006, to January 15, 2007.

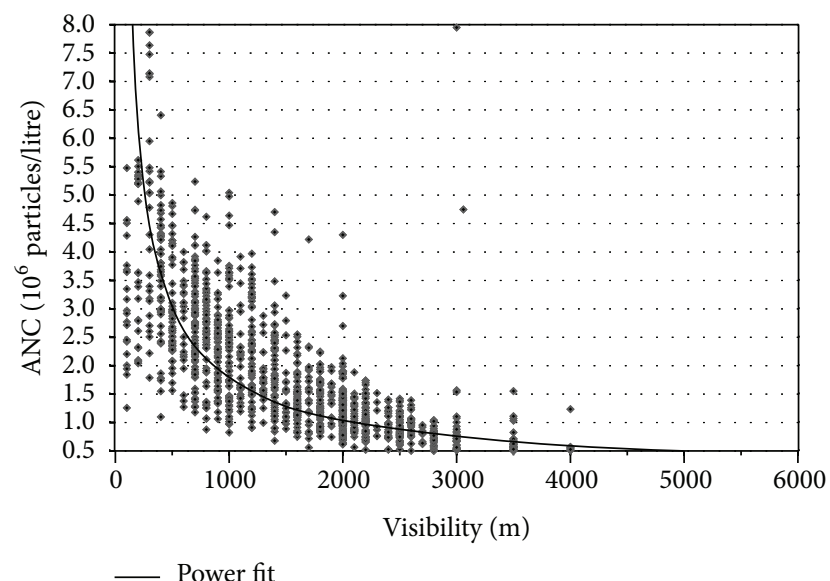

FIGURE 5: Scatter plot of visibility (m) and ANC (particle/litre).

$100 \mathrm{~m}$ (dense fog) while it is about $1 \times 10^{6}$ particle/litre for visibility of about $1000 \mathrm{~m}$ (fog). It is interesting to examine the relationship between ANC and visibility based on this data. Table 1 shows the correlation coefficient between ANC and visibility for linear, polynomial, logarithmic, power, and exponential fit and the ANC value for upper and lower bound that is complete limitation of visibility approaching zero and at $1000 \mathrm{~m}$, respectively. Though correlation coefficient is slightly better for exponential in comparison to power fit, the limit of visibility is more realistic for the latter and

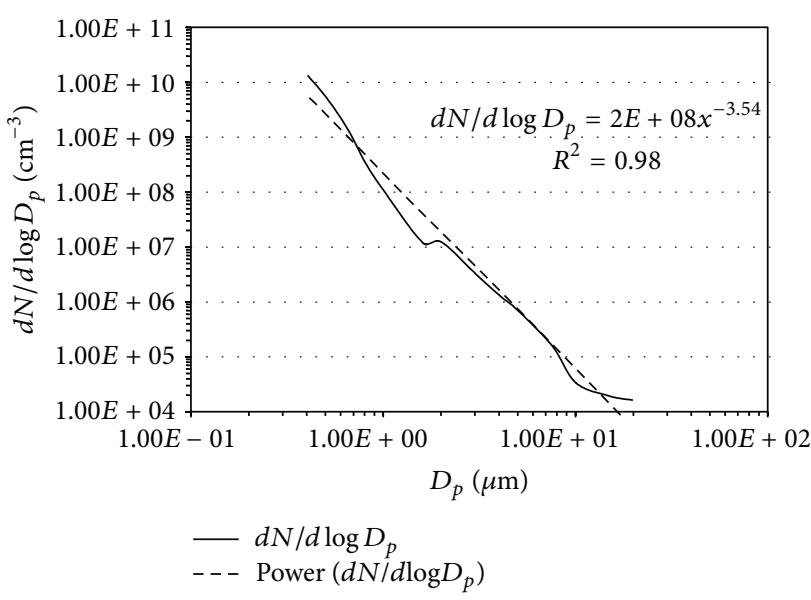

FIGURE 6: Log-normal aerosol number distribution with aerosol size spectrum during experiments.

hence selected. Hence, an empirical relation between aerosols number concentration (ANC) and visibility $\left(V_{\text {is }}\right)$ is selected here:

$$
\mathrm{ANC}=\alpha\left(V_{\mathrm{is}}\right)^{-\beta} .
$$

ANC is in particle/litre, visibility is in meter, $\alpha=4 \times$ $10^{8}$ (particle/litre) $\times$ (meter), and $\beta=0.77$. This relation demonstrates that ANC and $V_{\text {is }}$ are inversely intercorrelated.

Atmospheric aerosol size distributions are usually presented graphically in terms of the number, surface area, or volume distributions. Number distribution is preferred whenever extreme range of data is to be presented as also the importance of this distribution for visibility studies. A lognormal aerosol number distribution has been displayed in Figure 6 for the entire period and an empirical relation as follows is obtained with 0.98 as coefficient of determination:

$$
\frac{d N}{d \log D_{p}}=K D_{p}^{-p}
$$

where $K=2 \times 10^{8}$ and $p=3.54$.

$K$ is a constant related to the concentration of particles and $p$ is the slope of the number distribution curve [16]. Willeke and Whitby [11] also mentioned that $p$ is 3 for their observation. The value of $p$ generally lies between 2 and 4 . A size distribution with $p=3$ is called a Junge distribution [17]. Thus $p$ value is within the range shown by earlier studies, however, though somewhat higher than for Junge distribution. On the other hand, $K$ value is specific to concentration of particles that for the current measurements varies from $1 \times 10^{4}$ to $8 \times 10^{10}$. Continental aerosol particles with diameters larger than $\sim 0.2 \mu \mathrm{m}$ follow quite closely the above equation with $p=3$.

\section{Conclusions}

We examined the relationship between the aerosol number concentrations, particularly in low visibility/foggy conditions for a polluted urban environment in India with chemical 
TABLE 1: Correlation coefficient and ANC at $1000 \mathrm{~m}$ and for complete limitation of visibility approaching 0.

\begin{tabular}{lcccc}
\hline S. number & Curve fit & Correlation coefficient & \multicolumn{2}{c}{ ANC for visibility } \\
Approaching $0 \mathrm{~m}$ \\
\hline 1 & Linear & 0.74 & $2.12 \times 10^{6}$ & $3.0 \times 10^{6}$ \\
2 & Polynomial second order & 0.78 & $1.9 \times 10^{6}$ & $4.0 \times 10^{6}$ \\
3 & Logarithmic & 0.76 & $2.17 \times 10^{6}$ & $\approx 1.0 \times 10^{7}$ \\
4 & Power & 0.80 & $1.95 \times 10^{6}$ & $\approx 4.0 \times 10^{8}$ \\
5 & Exponential & 0.87 & $2.19 \times 10^{6}$ & $4.0 \times 10^{6}$ \\
\hline
\end{tabular}

composition dominated mainly by hydrophilic particles. Following are the main conclusions.

(i) A correlation between ANC and visibility for ANC-I and ANC-II are -0.76 and -0.53 , respectively, indicating that the size corresponding to ANC-I window, that is, $0.3 \mu \mathrm{m}$ to $0.8 \mu \mathrm{m}$, has far greater influence on visibility.

(ii) The formation of dense fog occurs when the number concentration of $0.3 \mu \mathrm{m}$ to $0.8 \mu \mathrm{m}$ particles reaches a significantly high value. As per the current measurements, threshold value of ANC is about $2 \times 10^{6}$ for $100 \mathrm{~m}$ and, for visibility of $1000 \mathrm{~m}$, it is about 1 $\times 10^{6}$. An empirical relationship between ANC (0.3$0.8 \mu \mathrm{m}$ ) and visibility is obtained for a highly polluted tropical urban site that may be verified with more observations and over different sites.

(iii) An empirical relationship for the lognormal aerosol number distribution is obtained with the aerosol diameter and compared with earlier studies.

(iv) Further experiments will help in modifying or validating the above findings. More research is needed to understand the ANC and visibility related issues by enhancing the scope of present research by including the measurements of ANC in lowest size range covering up to Aitken nuclei, its chemical composition, and other urban environments.

\section{Conflict of Interests}

The authors declare that there is no conflict of interests regarding the publication of this paper.

\section{Acknowledgments}

This research was partially supported by Department of Science and Technology (DST), Government of India as a research grant. The authors thankfully acknowledge Indian Meteorological Department (IMD), Delhi, for providing meteorological data. The authors would like to thank Mr. Ankur P. Sati for his kind assistance. They also thank the unknown reviewers for giving useful comments for improving the paper.

\section{References}

[1] H. R. Pruppacher and J. D. Klett, Microphysics of Clouds and Precipitation, Kluwer Academic Publishers, Boston, Mass, USA, 2nd edition, 1997.

[2] H. Kokkola, S. Romakkaniemi, and A. Laaksonen, "On the formation of radiation fogs under heavily polluted conditions," Atmospheric Chemistry and Physics, vol. 3, no. 3, pp. 581-589, 2003.

[3] M. Mohan, S. Bhati, and A. Rao, "Application of air dispersion modelling for exposure assessment from particulate matter pollution in mega city Delhi," Asia-Pacific Journal of Chemical Engineering, vol. 6, no. 1, pp. 85-94, 2011.

[4] J. L. Collett Jr. and S. N. Pandis, "The influence of drop sizedependent fog chemistry on aerosol processing by San Joaquin Valley fogs," Atmospheric Environment, vol. 33, no. 29, pp. 48174832, 1999.

[5] T. Elias, M. Haeffelin, P. Drobinski et al., "Particulate contribution to extinction of visible radiation: pollution, haze, and fog," Atmospheric Research, vol. 92, no. 4, pp. 443-454, 2009.

[6] K. Ali, G. A. Momin, S. Tiwari, P. D. Safai, D. M. Chate, and P. S. P. Rao, "Fog and precipitation chemistry at Delhi, North India," Atmospheric Environment, vol. 38, no. 25, pp. 4215-4222, 2004.

[7] P. Moenkkoenen, R. Uma, D. Srinivasan et al., "Relationship and variations of aerosol number and PM10 mass concentrations in a highly polluted urban environment-New Delhi, India," Atmospheric Environment, vol. 38, pp. 425-433, 2004.

[8] P. K. Pasricha, B. S. Gera, S. Shastri et al., "Role of the water vapour greenhouse effect in the forecasting of fog occurrence," Boundary-Layer Meteorology, vol. 107, no. 2, pp. 469-482, 2003.

[9] M. Mohan and S. Payra, "Influence of aerosol spectrum and air pollutants on fog formation in urban environment of megacity Delhi, India," Environmental Monitoring and Assessment, vol. 151, no. 1-4, pp. 265-277, 2009.

[10] S. Tiwari, S. Payra, M. Mohan, S. Verma, and D. S. Bisht, "Visibility degradation during foggy period due to anthropogenic urban aerosol at Delhi, India," Atmospheric Pollution Research, vol. 2, no. 1, pp. 116-120, 2011.

[11] K. Willeke and K. T. Whitby, "Atmospheric aerosols: size distribution interpretation," Journal of the Air Pollution Control Association, vol. 25, no. 5, pp. 529-534, 1975.

[12] S. Twomey, "Pollution and the planetary albedo," Atmospheric Environment, vol. 8, no. 12, pp. 1251-1256, 1974.

[13] J. H. Seinfeld, Atmospheric Chemistry and Physics of Air Pollution, John Wiley \& Sons, 1986.

[14] T. M. Peters, D. Ott, and P. T. O'Shaughnessy, "Comparison of the Grimm 1.108 and 1.109 portable aerosol spectrometer to the TSI 3321 aerodynamic particle sizer for dry particles," Annals of Occupational Hygiene, vol. 50, no. 8, pp. 843-850, 2006. 
[15] Portable Laser Aerosolspectrometer and Dust Monitor Model 1.108/1.109 User Manual, Technik GmbH \& Co. KG, http:// www.wmo-gaw-wcc-aerosol-physics.org/files/OPC-Grimmmodel--1.108-and-1.109.pdf.

[16] J. M. Wallace and P. V. Hobbs, Atmospheric Science: An Introductory Survey, Academic Press, New York, NY, USA, 2nd edition, 2006.

[17] C. E. Junge, Atmospheric Chemistry and Radioactivity, Academic Press, 1963. 

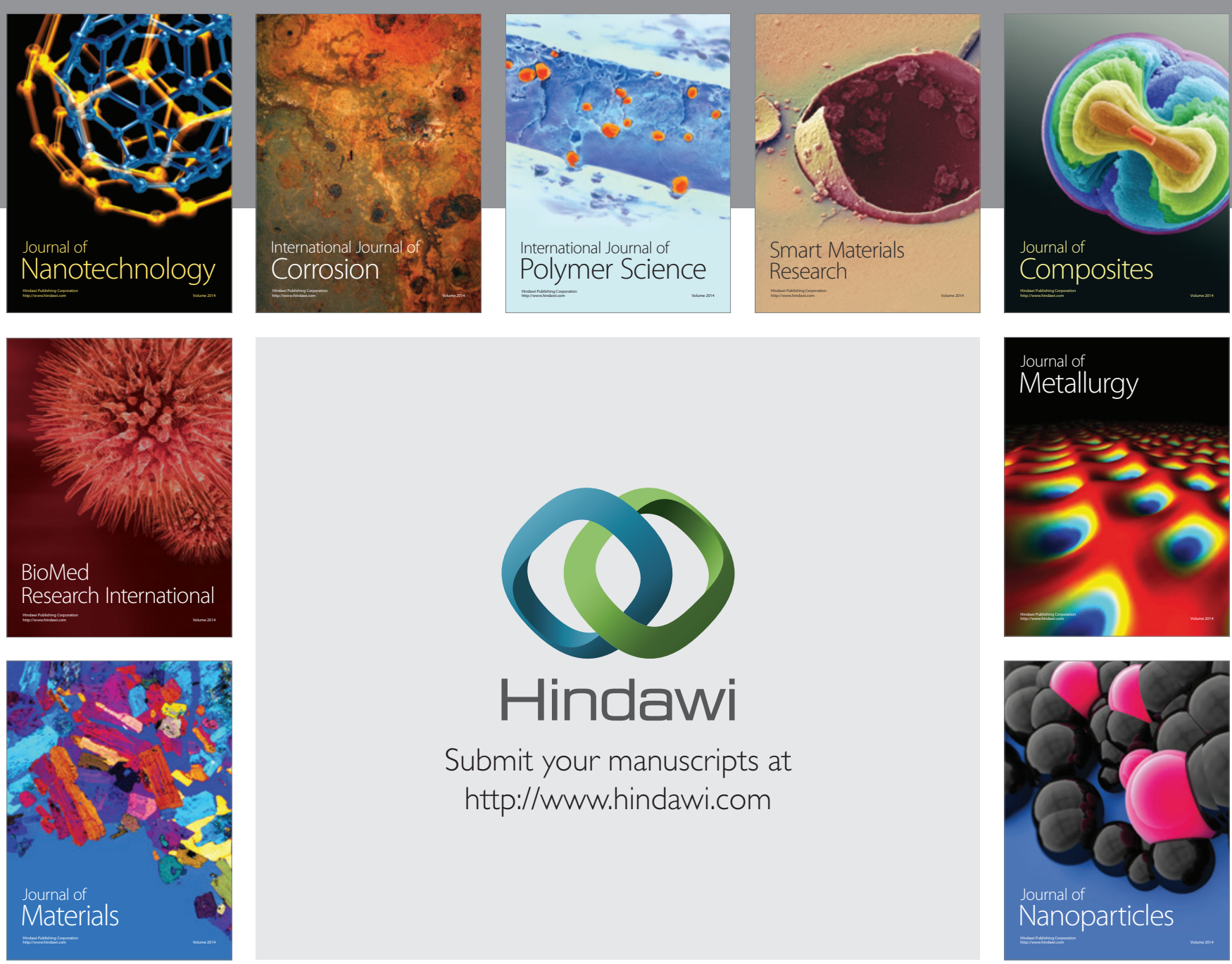

Submit your manuscripts at http://www.hindawi.com
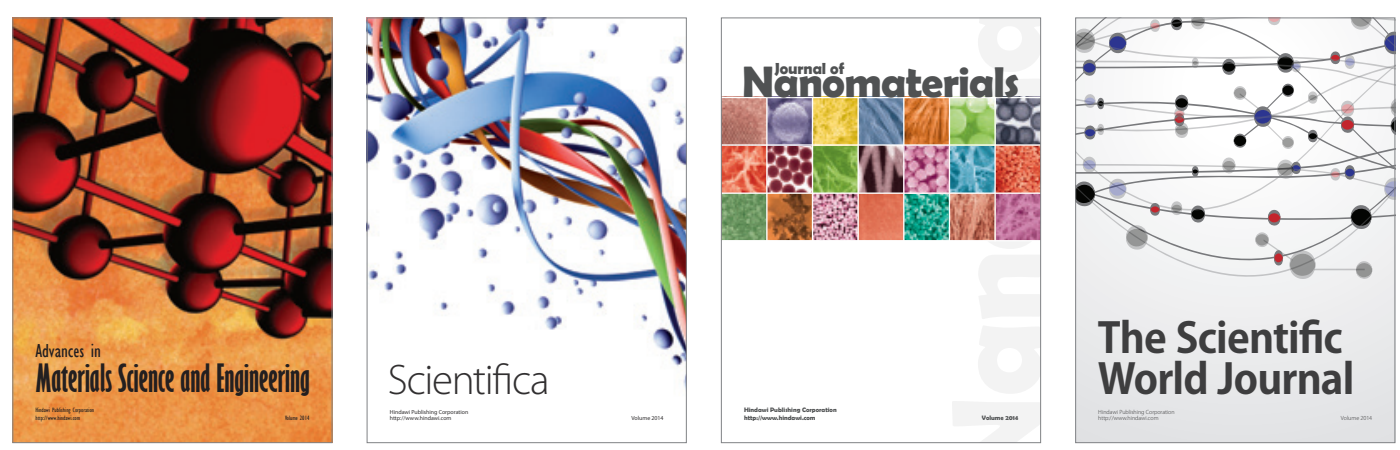

\section{The Scientific World Journal}
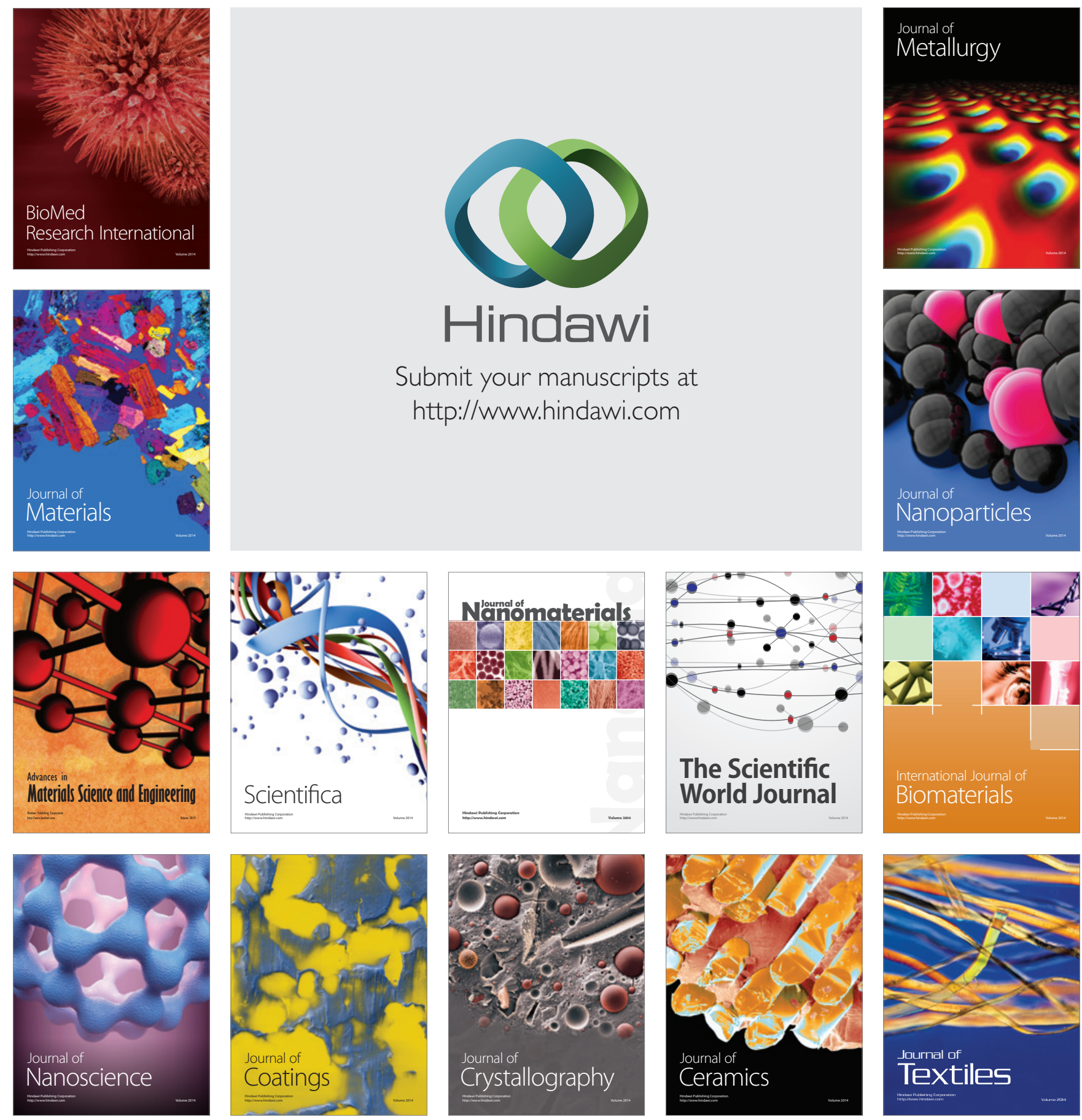